\title{
Study Kualitatif Supervisi Kepala Ruangan Dengan Pelaksanaan Pendokumentasian Asuhan Keperawatan Di Ruang Rawat Inap RSUD Praya Kab.Lombok Tengah Tahun 2019
}

\author{
Suswinda Yuli Sutomo, Arip Usman \\ Email: suswindayulisutomo@gmail.com
}

Departemen Keperawatan, Fakultas Kesehatan, Universitas Qamarul Huda Badaruddin, NTB, Indonesia

\begin{abstract}
ABSTRAK
Supervisi dalam keperawatan di tujukan untuk mengarahkan perawat dalam memberikan asuhan keperawatan. Penelitian bertujuan untuk melihat hubungan supervisi kepala ruangan dengan pelaksanaan pendokumentasian asuhan keperawatan di ruang rawat inap RSUD Praya tahun 2019. Jenis penelitian kualitatif, tehnik yang digunakan dalam penelitian kualitatif adalah dengan menggunakan metode wawancara mendalam kepada responden yang berjumlah 13 responden. Hasil dari penelitian kualitatif dengan menggunakan metode wawancara mendalam untuk mengetahui Penyebab rendahnya pendokumentasian asuhan keperawatan diantaranya karena tidak ada penghargaan bagi perawat yang melakukan pendokumentasian asuhan keperawatan, karena jumlah tenaga keperawatan yang tidak sesuai dengan jumlah pasien. Sesuai dengan hasil wawancara mendalam dengan responden : Sebagian responden mengatakan tidak ada penghargaan bagi perawat yang melakukan pendokumentasian asuhan keperawatan hanya mendapatkan pujian bagi perawat yang rajin dan sebagian responden mengatakan jumlah beban kerja yang tidak seimbang antara jumlah perawat dan pasien. Rekomendasi untuk manajemen keperawatan diharapkan selalu meningkatkan kemampuan supervisi kepala ruang, meningkatkan motivasi perawat dalam memberikan asuhan keperawatan termasuk pendokumentasian.
\end{abstract}

Kata Kunci: Struktur, Keterampilan, Dukungan, Keberlanjutan Supervisi dan Pendokumentasian Asuhan Keperawatan

\begin{abstract}
Supervision in nursing is aimed at directing nurses in providing nursing care. The study aimed to see the relationship of head room supervision with the implementation of documenting nursing care in inpatient wards of RSUD Praya in 2019. Techniques used in qualitative research is by using the method of in-depth interviews to respondents who numbered 13 respondents. The results of qualitative research by using in-depth interview method to determine the cause of low documentation of nursing care such as no rewards for nurses who do documenting nursing care, because the number of nursing personnel are not in accordance with the number of patients. In accordance with the results of in-depth interviews with respondents: Some respondents said there is no reward for nurses who do documenting nursing care only get praise for the diligent nurse and some respondents said the amount of workload is not balanced between the number of nurses and patients. Recommendations for nursing management are expected to always improve the ability of headroom supervision, increase nurse motivation in providing nursing care including documentation.
\end{abstract}

Keywords: Structure, Skill, Support, Supervision Sustainability and Documentation of Nursing Care

\section{A. LATAR BELAKANG}

Manajemen adalah ilmu dan seni mengatur proses pemanfaatan sumber daya manusia dan sumber daya lainnya secara efektif dan efisien untuk mencapai suatu tujuan tertentu [1]. Teori manajemen modern berasal dari Henry Fayol, 1925 pertama kali mengidentifikasi fungsi 
manajemen, perencanaan, organisasi, perintah, koordinasi dan pengendalian [2].

Manajemen merupakan proses pengumpulan dan pengorganisasian berbagai sumber dalam mencapai tujuan yang mencerminkan dinamika suatu ogranisasi.[3]

Proses manajemen meliputi kegiatan mencapai organisasi melalui perencanaan organisasi, pengarahan dan pengendalian sumber daya manusia, fisik dan teknologi [4]. Perawat sebagai tim kesehatan mempunyai peranan penting dalam meningkatkan kesehatan pasien, sehingga diperlukan kemampuan yang baik dalam melaksanakan perannya.

Salah satu upaya yang sangat penting dalam meningkatkan pelayanan keperawatan adalah meningkatkan sumber daya manusia dan manajemen keperawatan. Manajemen keperawatan adalah suatu proses bekerja melalui upaya anggota staf keperawatan untuk memberikan pelayanan keperawatan, pengobatan dan bantuan terhadap para pasien, dan tugas manejer keperawatan adalah merencanakan, mengorganisir, memimpin serta mengontrol keuangan, material, dan sumber daya manusia yang ada untuk memberikan pelayanan keperawatan seefektif mungkin bagi setiap kelompok dan keluarga mereka.[5]

Manajemen keperawatan adalah, manajemen keperawatan yang terdiri manajemen operasional dan manajemen asuhan keperawatan. Manajemen asuhan keperawatan dalam manajemen keperawatan adalah terlaksananya asuhan keperawatan yang ber kepada pasien. Pelaksanaan menajemen keperawatan didukung kemampuan dan keterampilan kepemimpinan dalam pelayanan keperawatan yang efektif dan efisien oleh setiap perawat apakah sebagai staf, ketua tim, kepala ruang, pengawas atau kepala bidang [6].

Pelaksanaan asuhan keperawatan diharapkan memenuhi harapan seorang menejer dan hasil yang diperoleh pasien/klien juga ber, maka diperlukan pengarahan dan pengawasan melalui kegiatan supervisi. Supervisi sebagai kegiatan yang merencanakan, mengamalkan, membimbing, mengajar, mengobservasi, mendorong, memperbaiki, mempercayai dan mengevaluasi secara berkesambungan anggota serta mengevaluasi sesuai dengan kemampuan dan keterbatas yang di miliki anggota. Kegiatan dalam supervisi yaitu perencanaan supervisi, pelaksanaan supervisi, evaluasi dan tindak lanjut, serta pendokumentasian hasil supervisi.[7]

Supervisi adalah suatu proses kemudahan untuk penyelesaian tugas- tugas keperawatan[8]. Seorang yang melakukan supervisi disebut dengan supervisor. Kegiatan supervisi adalah kegiatan - kegiatan yang terencana seorang menejer melalui aktifitas bimbingan, pengarahan, observasi, memotivasi dan pengawasan pada stafnya dalam melaksanakan kegiatan atau tugas sehari - hari[9]. Tujuan dari supervisi adalah untuk mengawasi dan mengevaluasi serta memperbaiki kinerja[10].

Peran supervisor sebagai pengawasan pada pelayanan dan administrasi pada unit tersebut[11]. Seorang supervisor keperawatan dalam menjalankan tugasnya sehari-hari harus memiliki kemampuan yaitu memberikan pengarahan dan petunjuk yang jelas sehingga dapat dimengerti oleh staf dan pelaksana keperawatan, memberikan saran, nasehat dan bantuan kepada staf dan pelaksanaan keperawatan, memberikan motivasi untuk meningkatkan semangat kerja, memberikan latihan dan bimbingan yang diperlukan oleh pelaksanan keperawatan, melakukan penilaian terhadap penampilan kinerja perawat, mengadakan agar asuhan keperawatan yang diberikan lebih baik[12].

Supervisi dapat dilakukan dengan dua cara yaitu supervisi langsung dan tidak langsung. Perawat menejer tingkat unit atau kepala ruangan melakukan tugas pengawasan atau supervisi kepada staf dalam pelayanan asuhan keperawatan mulai dari pengkajian, diagnosa keperawatan, perencanaan, implementasi, evaluasi serta pendokumentasian dengan baik.

Peran supervisor diatas dapat menentukan apakah pelayanan keperawatan (nursing care delivery) mencapai standart 
atau tidak. Hyrkas dan Pauninen - Ilmonen, menjelaskan bahwa supervisi klinik yang dilakukan dengan baik berdampak positif bagi quality of care atau kualitas pelayanan yang meningkat. Pengawasan yang baik dilakukan melalui kegiatan supervisi yang supportif[13].

Dokumentasi keperawatan adalah suatu mekanisme yang di gunakan untuk mengevaluasi asuhan keperawatan yang di berikan kepada klien. Fungsi pendokumentasian keperawatan bertanggung jawab untuk mengumpulkan data dan mengkaji status klien, menyusun rencana asuhan keperawatan dan menentukan tujuan, mengevaliasi asuhan keperawatan yang diberikan kepada klien. Fungsi pendokumentasian keperawatan bertanggung jawab dan menentukan tujuan, mengevaluasi efektivitas asuhan keperawatan dalam mencapai tujuan, mengkaji kembali dan merevisi rencana asuhan keperawatan.

Masalah yang sering terjadi di Indonesia pada rumah sakit pemerintah maupun swasta yaitu masih berkutat pada kelengkapan dokumentasi keperawatan yang kurang lengkap. Faktor yang mempengaruhi dalam pelaksanaan pendokumentasian adalah pengetahuan, usia, motivasi dan pengawasan. Berdasarkan hasil penelitian yang telah dilakukan oleh Agung Pribadi (2009), yang berjudul "Analisis Pengaruh Faktor pengetahuan motivasi dan persepsi perawat tentang supervisi kepala ruang terhadap pendokumentasian asuhan keperawatan di rumah sakit umum daerah Kelet di Jepara". Menunjukkan hasil adanya hubungan antara pengetahuan dalam pendokumentasian dan adanya hubungan antara supervisi kepala ruangan terhadap pelaksanaan asuhan keperawatan. Hal ini memunjukan betapa beratnya hubungan pengetahuan perawat dalam pedokumentasian dan supervisi kepala ruangan dalam pelaksanaan pendokumentasian asuhan keperawatan.

Kegiatan supervisi yang baik tidak terlepas dari kemampuan seorang manajer (kepala ruangan) dalam melakukan bimbingan, arahan serta memotivasi karyawannya dalam kegiatan, Termasuk dalam kegiatan supervisi yang dapat dilihat dari model supervisi yang dilakukan kepala ruang yang dapat di lihat dari kemampuan structure, skills, support dan sustainability kepala ruangan. Pelayanan dan pendokumentasian yang baik sehingga akan dapat mencapai visi, misi dan tujuan dari rumah sakit yang ada, termasuk rumah sakit yang berada di daerah seperti Rumah Sakit Umum Daerah (RSUD) Praya.

RSU Praya ialah salah satu Layanan Kesehatan milik Pemkab Lombok Tengah yang berbentuk RSU, dikelola oleh Pemda Kabupaten dan tergolong kedalam RS Kelas C. Layanan Kesehatan ini telah terdaftar dari 22/01/2013 dengan Nomor Surat ijin HK.07.06/III.3/75/2007 dan Tanggal Surat ijin 28/06/2007 dari Menkes RI dengan Sifat Tetap, dan berlaku sampai 5 Tahun. Setelah melakukan Proses Akreditasi Rumah sakit Seluruh Indonesia dengan proses Pentahapan I (5 Pelayanan) akhirnya ditetapkan dengan status Lulus. RSU ini bertempat di Jl. H. Lalu Hasyim, Kelurahan Tiwu Galih, Praya, Lombok Tengah, Indonesia. RSUD Praya saat ini memiliki 103 tempat tidur (TT) dengan menyediakan 51 TT untuk kelas III, dan mempunyai 10 ruang rawat inap dengan Bed Occupancy Rate (BOR) 61,17 \%, Length of Stay ( \pm 7 hari) [14]. 
Jumlah tenaga perawat di RSUD Praya berjumlah 310 orang, dan jumlah perawat di rawat inap berjumlah 226 orang dengan uraian sebagai berikut di ruangan.

Tabel 1. Distribusi Jumlah perawat berdasarkan ruangan di RSUD Praya Tahun 2019

\begin{tabular}{|l|l|l|}
\hline No & Ruangan & $\sum$ Perawat (orang) \\
\hline 1 & Flamboyan & 28 \\
\hline 2 & Tunjung 1 & 26 \\
\hline 3 & Tunjung 2 & 23 \\
\hline 4 & Melati & 21 \\
\hline 5 & Dahlia & 18 \\
\hline 6 & Angsoka & 30 \\
\hline 7 & Anggrek & 24 \\
\hline 8 & Mawar & 14 \\
\hline 9 & Seruni & 23 \\
\hline 10 & ICU & 19 \\
\hline 11 & Poli klinik & 23 \\
\hline 12 & IGD & 31 \\
\hline 13 & IBS & 30 \\
\hline & JUMLAH & $\mathbf{3 1 0}$ \\
\hline
\end{tabular}

Berdasarkan wawancara dengan 8 orang perawat pelaksana yang kurang tepat menjawab pertanyaan mengenai tujuan utama dan pentingnya pendokumentasian asuhan keperawatan. Namun secara umum perawat tersebut mengetahui bahwa pendokumentasian asuhan keperawatan tersebut harus di lengkapi dalam pengisian. Tetapi mereka beralasan bahwa pekerjaan mencatat asuhan keperawatan di rasakan cukup membebani, meskipun pada kenyataan jumlah perawat pelaksana masih berimbang di lihat dari Bed Occupancy Rate. perawat di ruangan juga tidak terbebani dengan tugas administrasi keuangan. Serta selama ini juga sudah ada pemberian insentif dalam bentuk jasa medis dan tunjangan hari raya. Berdasarkan hasil pengamatan diruang perawat kerjanya lebih banyak mengobrol dari pada membuat asuhan keperawatan.
Berdasarkan wawancara dengan perawat pengawas mengenai kegiatan supervisi kepala ruang tentang dokumentasi asuhan keperawatan, diperoleh informasi bahwa selama ini kepala ruangan melakukan supervisi sekali sebulan. Supervisi yang dilakukan tidak direncanakanya, serta tidak adanya evaluasi terhadap supervisi yang di lakukan. Perawat menganggap supervisi lebih di fokuskan pada masalah teknis dalam implemtasi pelayanan asuhan keperawatan. Sehingga perawat lebih menekankan kepada implementasi keperawatan karena mereka merasa hal tersebut yang lebih di perhatikan oleh kepala ruangan dan ada juga beberapa perawat mengatakan supervisi dilakukan terlalu singkat, tidak ada evaluasi terhadap apa yang di supervisi.

Setelah perawat melakukan implementasi tindakan tidak dilanjutkan dengan pencatatan perawat pada status pasien. Supervisi yang dilakukan belum terorganisir dengan jelas, mulai dari jadwal supervisi, kapan harus dilakukan supervisi, pemberian arahan, bimbingan yang jarang dilakukan, untuk mendorong perawat agar dapat lebih giat lagi dalam bekerja. Menurut model supervisi klinik seorang supervisor harus mampu membuat aturan, meningkatkan ketetampilan, memberikan dukungan kepada bawahannya untuk meningkatkan kemampuan dalam memberikan asuhan serta selalu mengevaluasi yang berkelanjutan terhadap apa yang di lakukan.

Pihak manajemen RS terutama bagian keperawatan berusaha untuk membuat kebijakan-kebijakan seperti menetapkan prosedur tetap mengenai pelaksanaan pelayanan asuhan keperawatan. Sementara itu dari segi kelengkapan, pihak manajemen juga sudah menyediakan tempat tersendiri 
(meja dan kursi) di setiap ruangan untuk menulis dokumentasi, menyediakan formulir dokumentasi asuhan keperawatan dan melakukan perubahan format menjadi bentuk ceklis yang lebih mudah dan sederhana, dan tidak menutup kemungkinan apabila ada usulan perubahan atas formulir tersebut untuk perbaikan dan mempermudah pendokumentasian asuhan keperawatan. dimana di RSUD Praya melaksanakan format asuhan keperawatan dalam bentuk ceklist. Dari segi pengembangan SDM, manajemen juga berusaha meningkatkan kualitas perawat dengan memberi kesempatan dan merencanakan pendidikan, pelatihan baik formal maupan non formal. Selain itu dalam pertemuan keperawatan manajemen juga mengingatkan untuk selalu meningkatkan pelayanan. Menurut teori faktor ganda Herzberg, motivasi identik dengan kepuasan kerja yang dipengaruhi oleh dua dimensi pekerjaan dasar. Faktor pertama adalah kondisi sekitar tugas yang kurang penting (extrincsic). Didalamnya tercakup kebijakan administratif perusahaan, kebersihan (kondisi) tempat kerja, hubungan antar pegawai, manfaat sampingan, dan peningkatan dalam pendapatan finansial. Herzberg menamakan kondisi itu sebagai faktor higienis, karena meskipun merupakan prasyarat penting bagi kepuasan bekerja, kondisi tersebut tidak membangkitkan performa tinggi. Faktor higienis lebih berpengaruh dalam menghilangkan halangan dalam lingkungan pekerjaan daripada terkait langsung dengan motivasi dalam pekerjaan. Faktor kedua adalah tugas itu sendiri (intrinsic). Apakah tugas itu memberikan perasaan telah mencapai sesuatu (prestasi/achievement) dan pengakuan (recognition) atas pencapaian itu. Apakah tugas itu (the work it self) cukup menarik, merupakan sesuatu yang ingin dikenang setelah selesai bekerja. Apakah tugas itu memberikan rasa keterlibatan dalam lingkungan pekerjaannya dan menimbulkan dorongan untuk menyelesaikannya (responsibility. Apakah tugas memberikan suatu tantangan sehingga memberikan adanya rasa pertumbuhan kemampuan (advancement). Kedua faktor tersebut harus dikelola dengan baik untuk menjaga motivasi tetap baik sehingga menampilkan kinerja yang diharapkan.

Rumah sakit selalu berharap terhadap pelayanan keperawatan yang diberikan oleh perawat akan lebih baik. Termasuk hal dalam pendokumentasian asuhan keperawatan yang diberikan, karena dokumentasi asuhan keperawatan merupakan bukti aspek hukum, komunikasi, jaminan dan untuk akreditasi. Melihat hal tersebut kepala ruangan dalam kegiatan supervisi harus mempunyai teknik/strategi, agar dokumentasi keparawatan lebih berkualitas.

Berdasarkan latar belakang dan studi pendahuluan tersebut, maka peneliti melakukan penelitian yang berjudul "Hubungan Supervisi Kepala Ruangan dengan Pelaksanaan Pendokumentasian Asuhan Keperawatan di Ruang Rawat Inap RSUD Praya Kabupaten Lombok Tengah Tahun 2019".

\section{B. METODE PENELITIAN}

Jenis penelitian ini adalah penelitian kualitatif dengan menggunakan pendekatan fenomologis, dalam pandangan fenomologis berusaha memahami arti peristiwa dengan kaitan-kaitannya terhadap orang-orang biasa dalam siatuasi tertentu pengamatan yang cermat dan mendalam (in-depth) yang menjawab terutama "mengapa" fenomena tertentu terjadi dalam ruang lingkup kontekstual yang spesifik. 
Tabel 2. Distribusi Informan

\begin{tabular}{|l|l|l|l|}
\hline No & \multicolumn{1}{|c|}{ Informan } & $\begin{array}{c}\text { Jumlah } \\
\text { informan }\end{array}$ & Keterangan \\
\hline 1 & $\begin{array}{l}\text { Kepala Seksi } \\
\text { Keperawatan }\end{array}$ & 1 Orang & $\begin{array}{l}\text { Wawancara } \\
\text { mendalam }\end{array}$ \\
\hline 2 & $\begin{array}{l}\text { Kepala } \\
\text { ruangan/ } \\
\text { bangsal }\end{array}$ & 6 orang & $\begin{array}{l}\text { Wawancara } \\
\text { mendalam }\end{array}$ \\
\hline 3 & $\begin{array}{l}\text { Perawat } \\
\text { pelaksana }\end{array}$ & 6 orang & $\begin{array}{l}\text { Wawancara } \\
\text { mendalam }\end{array}$ \\
\hline
\end{tabular}

\section{HASIL DAN PEMBAHASAN}

\section{Wawancara Terhadap Perawat}

a. Struktur

1) Pemecahan masalah yang harus dilakukan untuk mendukung kelengkapan dokumentasi

Sebagian responden berpendapat bahwa penambahan jumlah staf perawat, memfokuskan pekerjaan perawat, bimbingan rutin, menyederhanaan format pengisian askep, pemberian reward dan sangsi

"Paling tidak dengan menambah staf perawat di setiap ruangan, agar pekerjaan di ruangan tidak terlalu berat"

"Menekankan kepada Dokter untuk melelengkapi dokumentasi. Agar model catatan medik yang ada sekarang tidak menjadi beban kerja perawat juga"

"Saya sih menganggap perlu ada bimbingan rutin dari rumah sakit dan penambahan jumlah staf perawat"

"Jika diawali dengan penyegaran penulisan dokumentasi askep yang tepat dan benar, serta penyederhaan format pengisian askep"

"Saya sih gampang saja pemecahan masalahnya cukup dengan memberikan penghargaan minimal meningkatkan jasa pelayananlah terhadap staf perawat agar lebih termotivasi untuk melakukan"

"Mungkin kedepannya akan dibuat suatu sangsi yang berkaitan khusus tentang pendokumentasian asuhan keperawatan agar lebih tegas"

2) Manfaat penulisan dokumentasi asuhan keperawatan bagi staf perawat

Manfaat penulisan askep adalah sebagai alat komunikasi antara perawat yang lain.

"Perawat bekerja berdasarkan shift. Ada pagi, sore, dan malam. Dokumentasi tersebut sangat bermanfaat untuk alat komunikasi, sehingga antar perawat jaga bisa mengetahui kondisi pasien dari dokumentasi askep yang ada"

"Sebagai alat komunikasi perawat dengan perawat lain yang berbeda jam jaganya mbak"

3) Kepala Ruang melakukan bimbingan dalam dokumentasi keperawatan

Sebagian resonden menjawab bimbingan yang diberikan untuk pendokumentasian askep ada dan dilakukan ketika operan shif

"Karu saya hanya membimbing ketika kita melakukan operan, secara khusus sih ndak ada mbak"

"Bimbingan diberikan ketika kita operan saja sih mbak dan kalau ada yang keliru ketika dilihat status pasien saja mbak"

b. Keterampilan

1) Pengaruh supervisi Kepala Ruang pada pelaksanaan penulisan dokumentasi keperawatan

Supervisi kepala ruangan sangat berpengaruh terhadap pendokumentasian asuhan keperawatan 
"Berpengaruh mbak, dan kepala ruangan melakukan supervisi secara tidak langsung ketika pertemuan bulanan mbak"

"Sangat berpengaruh mbak, kan kepala ruangan yang mengarahkan kita menuliskan askep"

2) Staf perawat perlu melakukan pendokumentasian asuhan keperawatan yang dilakukan pada pasien

Sebagian responden menjawab sangat perlu untuk pertanggungjawaban terhadap tindakan keperawatan yang telah diberikan.

"Ya, sangat perlu untuk bukti sewaktu-waktu jika diminta pertanggung jawaban atas tindakan keperwatan yang telah dilakukan."

"Ya perlu, keuntungan dari segi hukum jika ada permasalahan di kemudian hari bisa dipertanggungjawabkan"

3) Secara rutin melakukan supervisi pada staf perawat tentang kegiatan kelengkapan dokumentasi asuhan keperawatan

Sebagian responden melakukan supervisi setiap hari ketika operan jaga perawat dan juga 1 bulan sekali

"Ya, Supervisi pencatatan askep dilakukan setiap hari dan juga bulanan. Setiap bulan kami bertemu dan catatan askep yang belum masuk Catatan Medis kami cek ulang",

"Ya, Supervisi secara rutin dilakukan sebulan sekali untuk membahas mengenai masalah diruangan dan juga sekalian mengenai pendokumentasian askep yang dilakukan oleh perawat"
4) Yang telah dilakukan untuk memotivasi staf perawat untuk meningkatkan pendokumentasian asuhan keperawatan yang dilakukan pada pasien

Disimpulkan bahwa kepala ruang memotivasi perawat secara lisan dalam setiap tindakan. Kecenderungannya tidak hanya untuk satu kegiatan misalnya hanya askep.

"Tidak ada kegiatan secara khusus sih yang saya berikan, hanya memberikan sanjungan saja ketika melakukan diskusi dengan seluruh staf perawat diruangan"

"Biasanya saya memberikan pujian kepada perawat yang rajin menuliskan askep"

5) Faktor yang mempengaruhi kelengkapan dokumentasi keperawatan

Sebagian responden berpendapat karena jumlah tenaga keperawatan yang tidak sesuai dengan jumlah pasien.

"Menurut Saya Perbandingan perawat - pasien tidak seimbang, pasien selalu penuh sementara jumlah perawat jaga hanya 3 atau 2 untuk shift sore/malam"

"Jumlah perawat disini yang tidak sebanding dengan jumlah pasien, sehingga perawat tidak sempat menulis askep"

c. Dukungan

1) Menuliskan dokumentasi asuhan keperawatan yang dilakukan pada pasien

Perawat tetap menuliskan askep walaupun tidak semua perawat menuliskan askep secara sempurna. 
"Ya, saya melakukannya. Menurut saya penulisan dokumentasi askep itu penting, suatu saat jika ada apa - apa dengan pasien bisa sebagai alat bukti kita"

"Saya menulis askep hanya bagian kolom tindakan saja karena yang paling penting untuk operan jaga"

2) Manfaat penulisan dokumentasi asuhan keperawatan bagi rumah sakit

Penulisan askep untuk akreditasi rumah sakit dan legalitas perawat

"Saya berpendapat dengan pendokumentasian askep yang baik, akan meningkatkan kerapihan dokumen yang ada sehingga mempermudah semua pihak ketika ada akreditasi Rumah Sakit"

"Manfaat untuk rumah sakit sih kalau askep bias digunakan untuk legalitas perawat dirumah sakit"

3) Faktor pendorong apakah yang saudara rasakan untuk melaksanakan dokumentasi asuhan keperawatan

Dorongan dari kepala ruangan untuk melakukan pendokumentasian askep

"Saya melakukan dokumentasi askep sih karena kepala ruangan yang mendorong untuk menulis askep itu"

"Kalau tidak didorong oleh Kepala Ruang besar kemungkinan saya tidak megerjakan dokumentasi askep"

4) Dorongan dari kepala ruangan untuk melakukan pendokumentasian askep

Motivasi penulisan askep adalah sebagai bukti telah melakukan dokumentasi tindakan keperawatan.

"Sebagai bukti bahwa saya telah merawat pasien dengan baik"
"Sebagai bukti bahwa perawat telah melakukan dokumentasi askep" d. Keberlanjutan

1) Penghargaan yang diperoleh bagi perawat yang selalu melakukan penulisan dokumentasi asuhan keperawatan

Tidak ada penghargaan bagi perawat yang melakukan pendokumentasian asuhan keperawatan hanya mendapatkan pujian bagi perawat yang rajin.

"Selama saya di sini belum pernah ada reward, bahkan tidak melakukanpun tidak apa - apa, paling - paling hanya ditegur tidak lama juga akan lupa lagi. Hanya dapat pujian aja kalau rajin"

"Mana ada mbak, gaji saya tidak ada apa lagi yang lain, paling Cuma dapat pujian aja"

2) Faktor penghambat/ kesulitan apakah yang saudara rasakan dalam upaya melaksanakan dokumentasi auhan keperawatan

Hambatan yang paling dirasakan adalah karena jumlah tenaga perawat tidak sebanding dengan jumlah pasien

"Kesulitan paling besar yang perawat rasakan adalah perbandingan jumlah perawat dengan jumlah pasien yang tidak seimbang. Kalau shift sore atau malam dengan 2 atau 3 perawat harus menangani lebih dari 10 pasien"

"Menurut saya faktor penghambat yang paling saya rasakan adalah kurang tenaga keperawatan, karena tidak sesuai dengan jumlah pasien yang banyak" 
3) Kepala Ruang melakukan evaluasi dalam dokumentasi keperawatan.

Sebagian responden menjawab evaluasi dilakukan ketika operan shif dan sebulan sekali.

"Ya, kepala ruangan melakukan evaluasi mbak ketika operan shif dan dilakukan secara bersama-sama dengan perawat lain yang ada diruangan ini”,

"Iya mbak, karu saya melakukan evaluasi, biasanya dilakukan evaluasi sebulan sekali mbak"

\section{KESIMPULAN}

Berdasarkan hasil wawancara mendalam kepada responden yaitu struktur sebagian resonden menjawab bimbingan yang diberikan untuk pendokumentasian askep ada dan dilakukan ketika operan shif

"Karu saya hanya membimbing ketika

kita melakukan operan, secara khusus sih ndak ada mbak"

"Bimbingan diberikan ketika kita operan saja sih mbak dan kalau ada yang keliru ketika dilihat status pasien saja mbak"

Hasil wawancara mendalam kepada responden yaitu Keterampilan sebagian responden berpendapat bahwa supervisi kepala ruangan sangat berpengaruh terhadap pendokumentasian asuhan keperawatan

"Sangat berpengaruh mbak, kan kepala ruangan yang mengarahkan kita menuliskan askep"

Dukungan hasil hasil wawancara mendalam kepada responden yaitu sebagian responden berpendapat bahwa mendapatkan dorongan dari kepala ruangan untuk melakukan pendokumentasian askep

"Saya melakukan dokumentasi askep sih karena kepala ruangan yang mendorong untuk menulis askep itu”"
"Kalau tidak didorong oleh Kepala Ruang besar kemungkinan saya tidak megerjakan dokumentasi askep"

Hasil wawancara mendalam kepada responden yaitu Keberlanjutan sebagian responden menjawab evaluasi dilakukan ketika operan shif dan sebulan sekali.

"Ya, kepala ruangan melakukan evaluasi mbak ketika operan shif dan dilakukan secara bersama-sama dengan perawat lain yang ada diruangan ini"

"Iya mbak, karu saya melakukan evaluasi, biasanya dilakukan evaluasi sebulan sekali mbak"

Penyebab rendahnya pendokumentasian asuhan keperawatan diantaranya karena tidak ada penghargaan bagi perawat yang melakukan pendokumentasian asuhan keperawatan, karena jumlah tenaga keperawatan yang tidak sesuai dengan jumlah pasien. Sesuai dengan hasil wawancara mendalam dengan responden : Sebagian responden mengatakan tidak ada penghargaan bagi perawat yang melakukan pendokumentasian asuhan keperawatan hanya mendapatkan pujian bagi perawat yang rajin.

"Selama saya di sini belum pernah ada reward, bahkan tidak melakukanpun tidak apa - apa, paling paling hanya ditegur tidak lama juga akan lupa lagi. Hanya dapat pujian aja kalau rajin",

"Mana ada mbak, gaji saya tidak ada apa lagi yang lain, paling Cuma dapat pujian aja"

Sebagian responden mengatakan jumlah beban kerja yang tidak seimbang antara jumlah perawat dan pasien.

"Menurut Saya Perbandingan perawat - pasien tidak seimbang, pasien selalu 
penuh sementara jumlah perawat jaga hanya 3 atau 2 untuk shift sore/malam" "Jumlah perawat disini yang tidak sebanding dengan jumlah pasien, sehingga perawat tidak sempat menulis askep".

\section{DAFTAR PUSTAKA}

[1] Hasibuan ,SP.(2005). Manajemen Sumber Daya Manusia. Jakarta, Bumi Aksara

[2] Marquis, B \& Huston. (1990). Ledership Roles and Management Function in Nursing. Philadelphia : Lippincott Company

[3] Swansburg. RC (2000). Kepemimpinan dan Manajemen Keperwatan , untuk perawat Klinis. Jakarta. EGC

[4] Arwani \& Heru Supriyanto,(2006), Manajemen Bangsal Keperawatan, Jakarta, EGC

[5] Gillies. (1994). Nursing Management: a System Approach, Philadelphia: W.B.Sounders Company
[6] Swansburg. RC (2000). Kepemimpinan dan Manajemen Keperwatan , untuk perawat Klinis. Jakarta. EGC.

[7] Saljan, (2005). Instrumen Evaluasi Supervisi.

[8] Swansburg. RC (2000). Kepemimpinan dan Manajemen Keperwatan , untuk perawat Klinis. Jakarta. EGC

[9] Arwani \& Heru Supriyanto,(2006), Manajemen Bangsal Keperawatan, Jakarta, EGC

[10] Gillies. (1994). Nursing Management : a System Approach, Philadelphia : W.B.Sounders Company

[11] Mc Eachen \& Keogh.. (2007). Nurse Management Demystified, A Self teaching Guide, New York : Mc Graw Hill

[12] Arwani \& Heru Supriyanto, (2006), Manajemen Bangsal Keperawatan, Jakarta, EGC.

[13] Supratman. (2008). Model - Model Supervisi Keperawatan Klinis. FIK.UMS

[14] profil RSUD Praya Kabupaten Lombok Tengah, (2019). 